\title{
USING AIR CONDITIONING TO DEMONSTRATE 1ST AND 2ND LAW ANALYSIS
}

\author{
Frank Wicks \\ Union College \\ Schenectady, New York
}

\begin{abstract}
2nd Law analysis techniques have the advantage of demonstrating the lost work associated with each non-ideal process in an engine or the extra work associated with each non-ideal process in an air conditioner, but the existing text books do not provide good examples of the applications of these techniques. Thus, a paper was presented and published for the 1995 conference to demonstrate the use of these techniques for fuel burning Carnot and Rankine cycles. This paper presents similar examples of the use of these techniques for air conditioning analysis.
\end{abstract}

\section{Introduction}

Recognizing that we live on a finite planet with limited fuel resources in the ground and with limited atmosphere to absorb the products of combustion, engineers will be continually and increasingly challenged to make our expanding modern society more energy efficient.

This means that all energy conversion processes and cycles should be continuously examined to establish how much fuel is being consumed and for the potential of improving efficiency with better cycles, heat exchangers and any other improved technologies.

A firm understanding of thermodynamics is the prerequisite for defining existing efficiencies and the opportunities and limits for such improvements. It is also noted that overall fuel consumption is typically a complicated function of many related efficiencies, which can be classified in various ways.

1st Law efficiencies can be described as the ratio of the useful energy achieved to the energy that must be provided. The efficiency of a boiler or furnace represents a 1st Law efficiency of a process, while the net efficiency of a power plant is the 1st Law efficiency of a cycle.
In contrast, 2nd Law efficiency is best described as the ratio of actual to ideaI performance. The isentropic efficiency of a turbine, pump, or compressor is the 2nd Law efficiency of a process, while the ratio of the actual efficiency of an engine to the ideal efficiency of an engine with the same heat source and sink describes the 2nd Law efficiency of a cycle.

Similarly, two methods can also be defined for evaluating the overall performance of a cycle. The first method can be defined as a 1st Law method because it examines the 1st Law energy balance for each process and for the total cycle, from which the ratio of desired energy achieved (i.e., the net work from engine) to what is supplied (i.e., the fuel) can be directly determined.

The second method requires the 2nd Law and thus is called a 2nd Law method. This method starts by determining the ideal performance of a cycle and then applies the 2nd Law to determine the irreversiiities of the individual processes. If it is an engine or power producing cycle, the irreversibilities represent lost work. If it is an air conditioning or refrigeration cycle, the irreversibilities are the extra work that must be supplied.

While both the 1st and 2nd Law methods should give the same net efficiency or performance, the 2nd Law method provides additional information since it quantities the lost work or extra work associated with each less than ideal process. Thus, the 2nd Law technique provides better guidance in terms of which of the processes represent the largest loss, and thus the best opportunities for improving performance.

Some thermodynamic text books describe the required principles, but do not provide good numerical examples to demonstrate their application. Thus, it is the author's goal to develop and present some such examples for inclusion in future text books. 
A 1995 paper by the author (Reference 1) used the familiar fuel burning Rankine cycle to demonstrate 1st and 2nd Law analysis. The 1st Law method presented the net plant efficiency as the product of the boiler efficiency and the cycle efficiency.

The 2nd Law method showed the same net efficiency could be cal culated by defining the efficiency of the ideal fuel burning engine or Wicks cycle (Reference 2) as a function of the maximum combustion product temperature minus the seven lost efficiencies associated with the superheating, boii and water heating sections of the boiler, the stack loss, the turbine, the condenser and the pump.

While both methods showed the same net efficiency, the 2nd Law method provided additional understanding of how much is lost in each process, and thus provided some guidance for the relative effectiveness of various efficiency enhancing efforts.

For example, the 1st law method showed a 90\% boiler efficiency that appeared to be very good, but the 2nd Law method showed that most of the lost efficiency was associated with the boiler because of the large temperature differences for the heat transfer process between the combustion products and the Rankine cycle working fluid. Thus, the 2 nd Law analysis was required to fully define the limits of a Rankine cycle.

The 2nd Law analysis also provided a basis for understanding the efficiency improving potential of a combined cycle comprised of an internal combustion gas turbine topping cycle and an external combustion steam turbine bottoming cycle.

It is noted that the application of 2 nd law analysis techniques requires obtaining the entropy of the working fluid to a high degree of precision, which was difficult to do with the tables in the back of the book, but can be done quite readily with the newly available thermal physical properties on computer disk.

This paper will describe similar but somewhat different 1st and 2nd Law methods for analyzing air conditioning with the belief that these examples should also be included in future thermodynamic text books.

\section{Evaluating an Ice Air Conditioner .}

The first example is a one ton system (i.e.,
$12,000 \mathrm{Btu} / \mathrm{hr}$ ) in which ice is used for cooling and with the inside air temperature of $70 \mathrm{~F}$ and the outside air temperature of $100 \mathrm{~F}$ as shown in Figure 1 in which ice is supplied to the tank at $32 \mathrm{~F}$ and $32 \mathrm{~F}$ water drains from the tank. Heat at $70 \mathrm{~F}(530 \mathrm{R})$ is released by the house air and absorbed by the ice at 32 F (492 R).

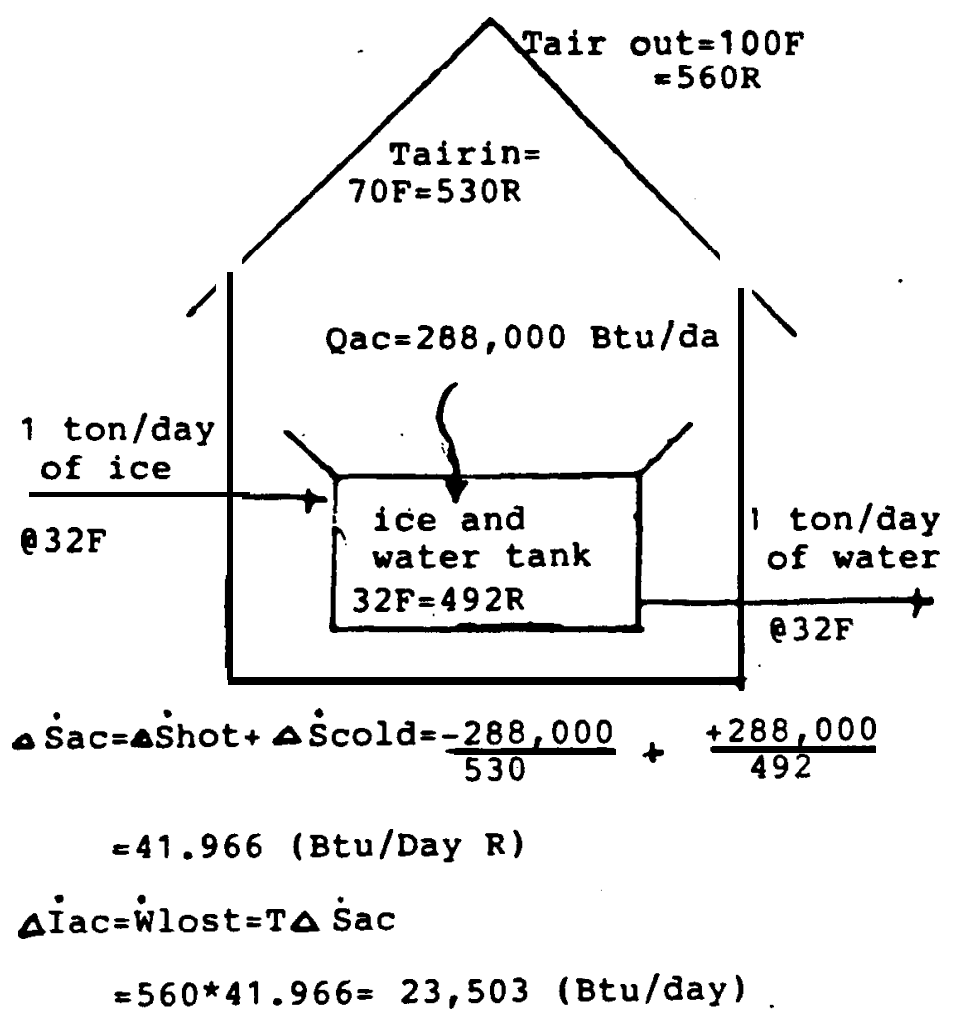

Figure $1 \mathrm{~A}$ one ton ice air conditioner by melting one ton of ice per day which absorbs 288,000 (Btu/day).

It is noted that the amount of cooling that is provided by melting one ton or $2,000 \mathrm{lbs}$ of ice per day with a heat of fusion of $144 \mathrm{Btu} / \mathrm{lb}$ corresponds to $288,000 \mathrm{Btu} /$ day or $12,000 \mathrm{Btu} / \mathrm{hr}$. It is also noted that the process between the house air and the melting ice is irreversible since heat is transferred over a $38 \mathrm{~F}$ temperature difference.

Thus there is a net entropy increase of 41.966 (Btu/day R) as a result of this heat transfer over a temperature difference as shown in Figure 1. The còrresponding irreversibility or lost work is 23,503 (Btu/day) which is attained by the 2nd Law in the form of multiplying this entropy production by the temperature of the infinite heat reservoir which is the $100 \mathrm{~F}$ outside air temperature. 
This suggests that there is some ideal or reversible method for using the resource of 1 ton of ice per day and performing the same job of removing the same 28S,000 (Btu/day) of heat from the house such that an extra work will result from this ideal technique that is equal to the lost work by the nonideal method.

Such an ideal system is shown in Figure 2. It consists of operating a reversible Carnot cycle engine using the outside air as a heat source and a ton of ice per \&y at 32 F (492 R) for the cold reservoir, and a

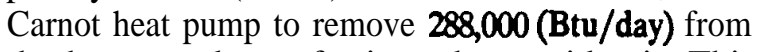
the house and transfer it to the outside air. This Carnot engine will produce 39,S05 (Btu/day) of work and the Carnot air conditioner will consume only 16,302 (Btu/day) of work, which yields an extra work of $23 \$ 03$ (Btu/day) which is the amount of lost work found in Figure 1 for the non-ideal technique.

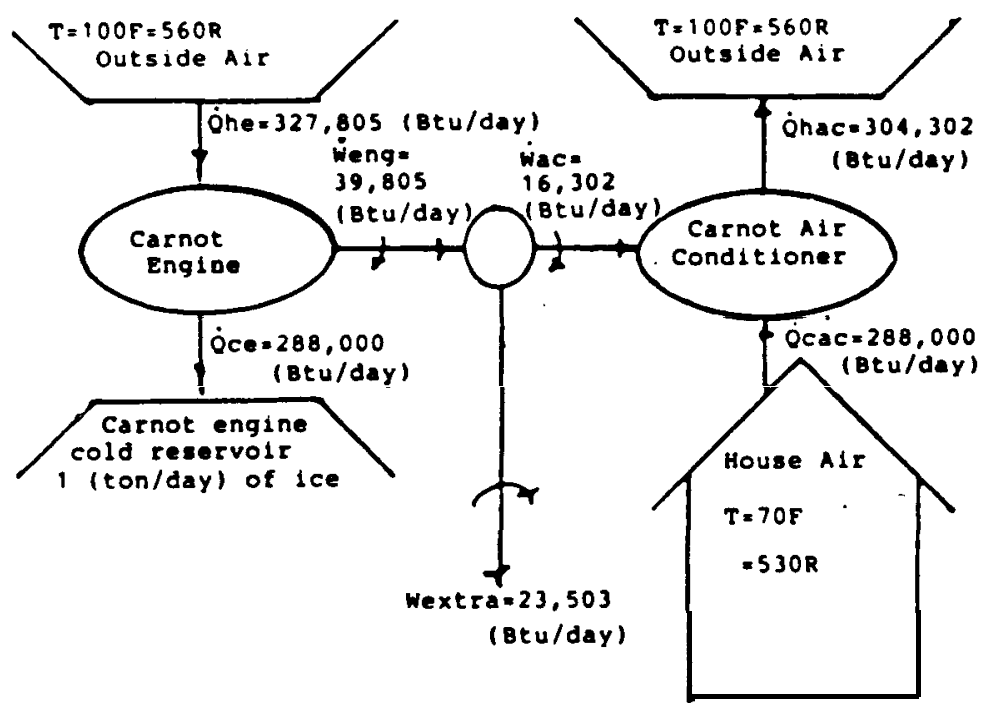

Figure 2 A reversible method for utilizing one ton of ice per day while providing 1 ton $=\mathbf{2 8 8 , 0 0 0}$ (Btu/day) of heat removal from the building.

\section{Evaluating an Electric Compression Air Conditioner}

We now extend these 1st an 2nd Law techniques to the evaluation of cooling the same house with the same inside and outside air temperatures by means of a one ton or 285,000 (Btu/day), electric compression air conditioner show in Figure 3.

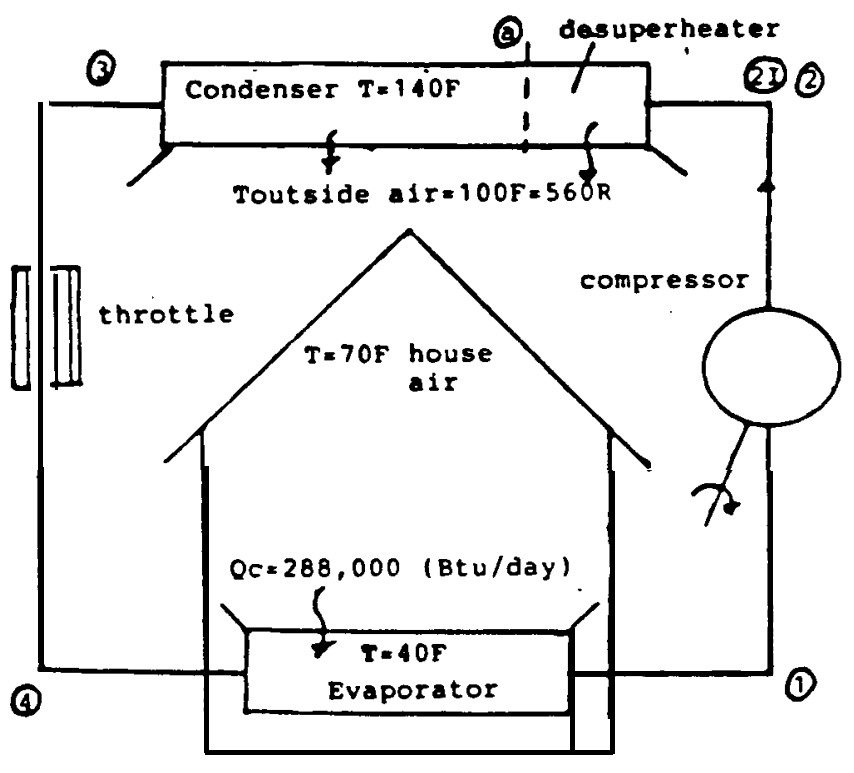

Figure 3 A one ton electric compression air conditioner.

The condensing unit is defined in terms of the desuperbeating section and the condensing section, with the condensing occurring at $140 \mathrm{~F}$ which is $40 \mathrm{~F}$ higher than the outside air temperature. The compressor has a $70 \%$ isentropic efficiency and an adiabatic throttle reduces the saturated high pressure liquid from the condenser to a mixture to the evaporator.

It is noted that there are five irreversible processes associated with this air conditioner corresponding to the compressor, the desuperheater, the condenser, the throttle and evaporator. A property table and 1st Law process and cycle table is developed to determine the power requirement.

We assume the working fluid is Freon 22 and obtain the properties at each defined point in the process. These properties are first obtained from the pressure vs enthalpy chart in Figure 4 and then from the computer based data for more precision and summarized in Table 1. 


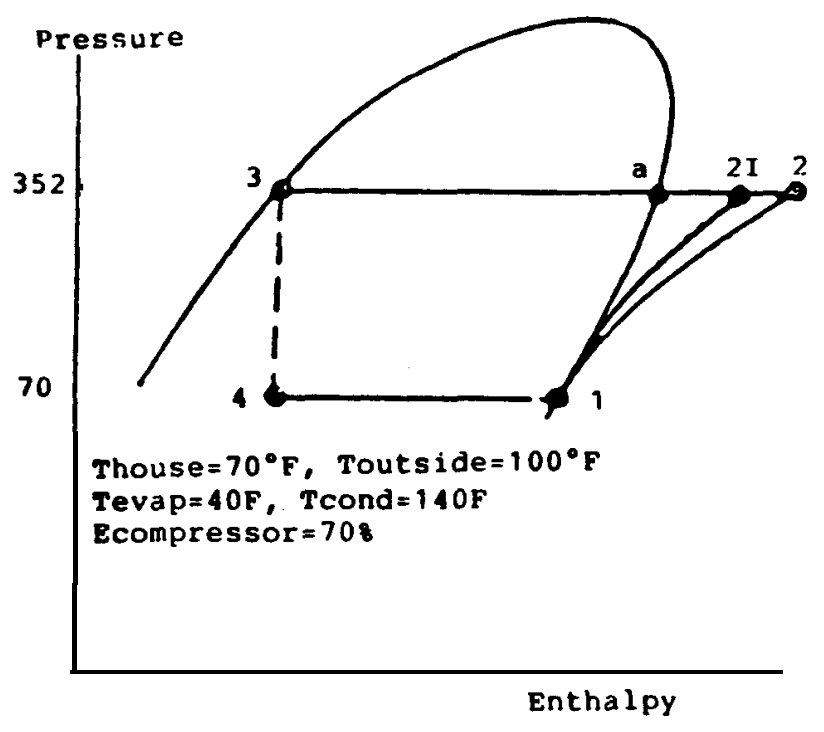

Figure 4 Superimposing an electric compression air conditioner on the thermal physical properties diagram of the freon.

These properties are nowobtairted with more precision from the computer properties for Freon 22 to both confirm consistency and to provide the additional level of precision that is required for the comparative analysis and these values are shown in Table I.

\section{Table I}

Property Table for Electric Compression Air Conditioner Using Computer Based Property Data for Ease and Precision

\# $P(p s i a) T(F) T(R) v(f t=3 / l b) h(B t u / l b) \times(\%) s(B t u / l b R)$

$\begin{array}{llllllll}1 & 69.6 & 30 & 490 & .78210 & 107.28 & 100 & .2218 \\ \text { 2J } & 3 s 1.9 & 188 & 648 & .178 s 1 & 12 s .03 & - & 2218 \\ 2 & 3 s 1.9 & 221 & 681 & .19808 & 132.64 & - & .2333 \\ \text { a } & 3 S 1.9 & 140 & \mathbf{6 0 0} & . \mathbf{1 4 4 1 8} & \mathbf{1 1 2 . 9 3} & 100 & .2023 \\ 3 & 3 S 1.9 & 140 & 600 & .01552 & \mathrm{~S} 2.53 & \mathrm{O} & .10163 \\ 4 & 69.6 & 30 & 490 & \mathbf{. 3 0 6 9 0} & \mathbf{5 2 5 3} & 38 & .10997\end{array}$

The 1st Law applies to each or the five processes in this cycle and also for the net cycle with results are tabulated in Table II, and that the compressor input which is also the rate of work to perform the air conditioning requirement is 117,082 (Btu/day).
Table II

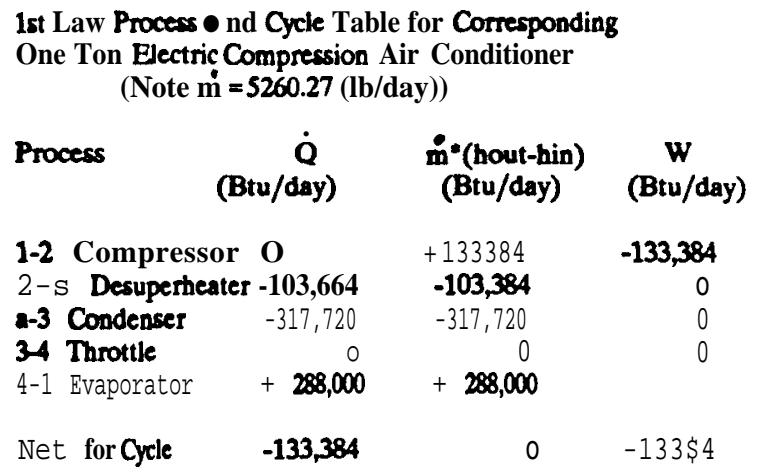

We now believe that we could get the same required work by the 2 nd Law method, where the total work should be the ideal work of 16,302 (Btu/hr) we found for the ideal Carnot air conditioner in Figure 2 plus the extra work associated with each non-ideal process.

Each of the five non-ideal processes will be characterized as a producer of entropy. The evaporator, desuperheater and condenser produce entropy because of heat transfer over a temperature difference. The compressor and throttle valve are adiabatic, but produce entropy because of internal friction, and thus their entropy production is the Freon flow rate times the entropy increase from inlet to outlet.

The entropy production for each process is now calculated and then multiplied by the outside temperature to obtain the extra work associated with each process and for the total cycle and these results are summarized in Table III which shows a net extra work of 117,802 (Btu/day).

The Carnot work plus the extra work becomes 133,384 (Btu/day) from Table III should and does corresponds to the $\mathrm{X33,384}$ (Btu/day) compressor work from the 1st Law method as was shown in Table II. 
Table III

2 ad Law process and Cycle Table to Summarize Entropy Production Rate and Irreversibility (= Extra Work) Rate

\begin{tabular}{|c|c|c|}
\hline Process & $\begin{array}{l}\text { del } \dot{\mathbf{S}} \\
\text { Biv/day) }\end{array}$ & $\begin{array}{c}\text { Extn Wort }=\text { Tinf'del S } \\
\text { (Btw/dayR) }\end{array}$ \\
\hline $\begin{array}{l}\text { 1-2 Comprewor } \\
\text { 2- Desupertheater } \\
\text { 8-3 Coodenser } \\
\text { 34 Throttle } \\
\text { 4-1 Enporntor }\end{array}$ & $\begin{array}{r}60.493 \\
\mathbf{2 2 0 4 6} \\
\mathbf{3 7 . 0 0 6} \\
\mathbf{4 3 . 8 7 0} \\
\boldsymbol{4} \mathbf{4 . 8 6 0}\end{array}$ & $\begin{array}{l}33,876 \\
12,346 \\
21,171 \\
24 ? s 67 \\
25,122\end{array}$ \\
\hline Net for Cycie & 209.075 & 117,082 \\
\hline
\end{tabular}

Notes:

1. Wideal is the Carno AC work in Figure 2.

2. The Wot from the 1st Law method as shown in Table II is the same as Wnet from the 2nd Law method which is the sum of the for Carnot Cycle Wideal from Figure 2 and Wextra from Table III.

\section{Discussion}

The author believes that the analysis of these two air conditioning systems by two different methods and obtaining the same results provides another profound and important demonstration of 1st and 2nd Law performance analysis techniques.

This belief has been confirmed by the students who have performed this type of analysis as homework assignments, in which they have also used other refrigerants which will have different property values, but still yield the same power requirement result.

While the 1st and 2nd Law methods both yield the same result, the 2nd Law method provides additional information of how much extra work is associated with each process, and this provides the additional guidance in how best to improve performance.

Thus, the students can evaluate the relative benefits of enhanced heat transfer by more area or other techniques in the evaporator or condenser, a more efficient compressor, or possibly replacing the throttle value with a power work producing expander.

\section{Acknowledgement:}

The autbor thanks the Niagara Mohawk Power Corporation for the energy related projects grant that Lelped make this work possible.

\section{References:}

1. Frank Wicks, 'Using Fuel Burning Carnot and Rankine Cycles to Demonstrate 1st and 2nd Law Efficiency Analysis", presented at and published in the proceedings of the 1995 Annual American Society for Engineering Conference in Amabeim, Volume 1, pp 450458.

2. Frank Wicks, The Thermodynamic Theory and Desige of an Ideal Fuel Burning Engine", presented at and published in the Proceedings of the 1991 Intersociety Energy Conversion Engineering Conference in Boston, $\mathrm{PP} 474$ 481.

\section{FRANK WICKS}

Professor Frank Wicks received $\bullet$ BMarineE from SUNY Maritime in 1961, - MSEE from Union College in 1966 and a $\mathrm{PhD}$ in Nuclear Engineering from RPI in 1976. He was Commissioned in the Navy and served as a shipboard engineering officer, and then as a General Electric aircraft engine, turbire, nuclear and electric utility systems engineer. He was Supervisor of the RPI Nuclear Reactor and Operations and has served at Union College since 1988. Dr Wicks is • Professional Engineer and a member of AAAS, AIAA, ANS, ASCE, ASEE, ASME, IEEE, Sigma $X_{i}$, Pi Tau Sigma, and Tau Beta Pi and holds several energy conversion and conservation related patents. He is also a licensed pilot for engine powered aircraft and gliders. 